\title{
Renal impairment and moderate alcohol consumption in the elderly. Results from the Italian Longitudinal Study on Aging (ILSA)
}

\author{
Alessandra Buja ${ }^{1}$, Emanuele Scafato ${ }^{2}$, Bruno Baggio ${ }^{3}$, Giuseppe Sergi ${ }^{4}$, \\ Stefania Maggi ${ }^{5}$, Giuseppe Rausa' ${ }^{1}$, Angela Basile ${ }^{1}$, Enzo Manzato ${ }^{4}$, Silvia Ghirini ${ }^{2}$ \\ and Egle Perissinotto ${ }^{1, *}$, for the ILSA Working Group \\ 'Department of Environmental Medicine and Public Health, University of Padua, Via Loredan 18, 35128 Padua, \\ Italy: ${ }^{2}$ sstituto Superiore di Sanità, Rome, Italy: ${ }^{3}$ Department of Medical and Surgical Sciences, Nephrology \\ Division, University of Padua, Padua, Italy: ${ }^{4}$ Department of Medical and Surgical Sciences, Geriatrics Unit, \\ University of Padua, Padua, Italy: ${ }^{5}$ Institute of Neurosciences, CNR-Padua, Italy
}

Submitted 13 July 2010: Accepted 14 March 2011: First published online 1 June 2011

\begin{abstract}
Objective: The influence of moderate alcohol consumption on renal function is not clear in elderly people. The aim of the present study was to investigate the relationship between alcohol consumption and renal function, expressed as serum creatinine levels and glomerular filtration rates (GFR), in an elderly population.

Design: Perspective cohort study.

Setting: Population-based study on an elderly Italian population.

Subjects: A sample of 3404 Italian people (1619 women and 1785 men), aged 65-84 years, from the Italian Longitudinal Study on Aging (ILSA).

Results: Prevalence and cumulative risk of impaired renal function (defined as GFR $\leq 60 \mathrm{ml} / \mathrm{min}$ ) were estimated by sex and alcohol consumption groups. Logistic regression analysis adjusting for confounders (age, education, smoking, BMI and medications) and intermediate factors (blood cholesterol and fibrinogen, systolic hypertension and diabetes) showed that alcohol consumption level was not significantly related to the prevalence of mild renal impairment in elderly women. In men, both prevalence and incidence results seemed to suggest an inverse linear relationship between moderate alcohol consumption and the risk of mild renal impairment. A U-shaped association was shown for women at the incidence phase, suggesting a higher risk of developing renal impairment for women who drink more than $24 \mathrm{~g}$ alcohol/d.

Conclusions: Our results suggest that, in accordance with the recommendations on alcohol consumption in the elderly, moderate quantities of alcohol are not injurious to renal function in elderly men.
\end{abstract}

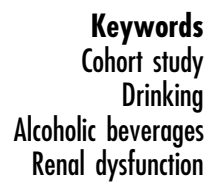

Keywords Drinking Renal dysfunction
The literature evidence indicates that moderate alcohol consumption is associated with a lower risk level for a number of cardiovascular risk factors such as lipoprotein, glucose metabolism, haemostatic and inflammatory markers in the elderly ${ }^{(1)}$. Accordingly, a J-shaped relationship between alcohol consumption and risk for CHD morbidity and mortality is broadly reported in elderly persons ${ }^{(2)}$. Several prevalence and longitudinal studies have shown that the well-known age-dependent renal decline is strongly associated with cardiovascular risk factors in the elderly ${ }^{(3)}$, but to date the relationship between alcohol consumption and renal function is still unclear.

The abuse of alcohol is known to be associated with renal alterations, including tubular dysfunction, acute tubular necrosis and IgA nephropathy ${ }^{(4)}$. However, scarce evidence has been provided on a role of moderate alcohol consumption on kidney function in adults. A recent study on 65601 middle-aged Chinese men suggested an inverse relationship between alcohol consumption and the risk of end-stage renal disease ${ }^{(5)}$. In another large prospective cohort study, Schaeffner et al. reported an inverse relationship between alcohol consumption and the risk of renal dysfunction in apparently healthy men ${ }^{(6)}$. A prospective observational study on nurses found no significant association between alcohol consumption and the onset of renal dysfunction ${ }^{(7)}$ in women. In addition, in the second National Health and Nutrition Examination Survey, alcohol was unrelated to any presence of chronic kidney disease in 9082 adults $^{(8)}$. On the other hand, in a casecontrol study Perneger et al. ${ }^{(9)}$ found that consumption of 
two alcoholic drinks daily corresponded to a fourfold increase in the risk of end-stage renal disease, whereas a case-control study by Vuppituri and Sandler ${ }^{(10)}$ identified no increased risk of chronic kidney disease among regular alcohol consumers. While the association between alcohol consumption and renal function in adult populations is still under debate, information on elderly populations is lacking ${ }^{(11)}$.

The aim of the present longitudinal study was to investigate the association between alcohol consumption and prevalence and incidence of renal function impairment in an elderly population. The study considered a representative sample of an elderly Italian population, for whom alcoholic beverages are traditionally part of the diet.

\section{Methods}

\section{Study sample}

Our sample population was drawn from the Italian Longitudinal Study on Aging (ILSA) cohort. The ILSA is a population-based longitudinal study on the health of Italians aged 65-84 years. The main aims of ILSA were to study the prevalence and incidence rates of common chronic conditions (IHD, hypertension, congestive heart failure, arrhythmia, intermittent claudication, type 2 diabetes mellitus, impaired glucose tolerance, thyroid dysfunction, dementia, parkinsonism, stroke and peripheral neuropathy), to assess physical and mental functional status in the older population, and to identify their risk factors and protective factors. A random sample of 5632 individuals was identified using the demographic lists at the registry offices of eight Italian municipalities from a total target population of 44737 individuals. The full design of the ILSA has been published elsewhere ${ }^{(12)}$. In brief, the study included prevalence and incidence surveys. The first survey started in March 1992 and the second in September 1995, with a mean follow-up of 3.5 years. Each survey consisted of two phases: a screening phase for all participants, which included a personal interview, a physical examination, and laboratory and diagnostic tests; and a second phase for participants who tested positive for one or more diseases, who underwent a clinical assessment by board-certified physicians (geriatricians or neurologists) and a review of their medical records. Informed consent was given according to institutional guidelines. All of the study phases were conducted in accordance with the Declaration of Helsinki.

At baseline, 5462 participants (2728 women and 2734 men) were eligible for the ILSA. The present study excluded from the analysis all those lacking baseline information on alcohol consumption ( $n$ 968) and those whose ratio of aspartate aminotransferase (AST) to alanine aminotransferase (ALT) was higher than $2 \cdot 0$ when they also showed AST $>45 \mathrm{U} / 1$ and/or ALT $>55 \mathrm{U} / 1$ ( $n$ 10), to exclude those suspected to be alcohol abusers.
Among the remainder ( $n$ 4484), 1080 participants who had no serum creatinine data at baseline were also ruled out. In the end, 3404 participants (1619 women and 1785 men) were analysed at the prevalence phase, while 1539 (653 women and 886 men) whose serum creatinine was assessed at the baseline and at follow-up visits were included in the longitudinal analysis. Details on attrition numbers by gender are given in Figs 1 and 2. A preliminary descriptive analysis (data not shown) showed for both women and men that participants included in the analysis of prevalence data were significantly younger, with lower education, lower prevalence of dementia and higher prevalence of arrhythmia and hypertension than participants who were not included. Among participants included in the analysis, the proportion of abstainers was significantly lower. Differences due to attrition were found also at the incidence phase because the participants included were significantly younger, with lower blood fibrinogen levels and less affected by diabetes and dementia.

\section{Study variables and definitions}

\section{Questionnaire}

The questionnaire used to collect information included questions on age and education; lifetime hospital admissions; current use of medications (including antihypertensive medications (i.e. diuretics, $\beta$-blockers, angiotensin-converting enzyme inhibitors or calcium antagonists), non-steroidal anti-inflammatory drugs and cardiac drugs (i.e. diuretics, nitrates, antiarrhythmic drugs and cardiac glycosides)); and food consumption (daily or weekly frequency of consumption of the main categories of foods).

To collect information on drinking habits, the participants were asked: 'Do/Did you drink wine regularly (nearly every day)?', 'Do/Did you drink beer regularly (nearly every day)?' and 'Do/Did you drink spirits/appetizers/laced coffee?' The history of alcohol consumption was assessed by asking people to list the periods of their life with different levels of consumption (questions on amounts based on a standard $125 \mathrm{ml}$ glass for wine and beer, and number of shots for spirits, and on the periods of consumption from age... to age....). Abstainers were identified as those answering 'no' to the questions above and reporting that their current and past consumption was null. Drinkers were identified as those answering 'yes' to at least one of the above questions, and were classified as former and current drinkers. Former drinkers were those no longer drinking alcoholic beverages at the time of the survey. Current drinkers were considered as those who reported alcohol consumption at the time of the interview, and current consumption was the amount reported at the time of the interview. Alcohol intake was assessed in terms of glasses of wine or beer per day and number of shots of spirit per day, month or year. A trained interviewer converted the amount of each beverage into $\mathrm{ml} / \mathrm{d}$ using a standard measure of $125 \mathrm{ml}$ per glass of wine and beer, while one shot of spirit corresponded to $40 \mathrm{ml}$. 


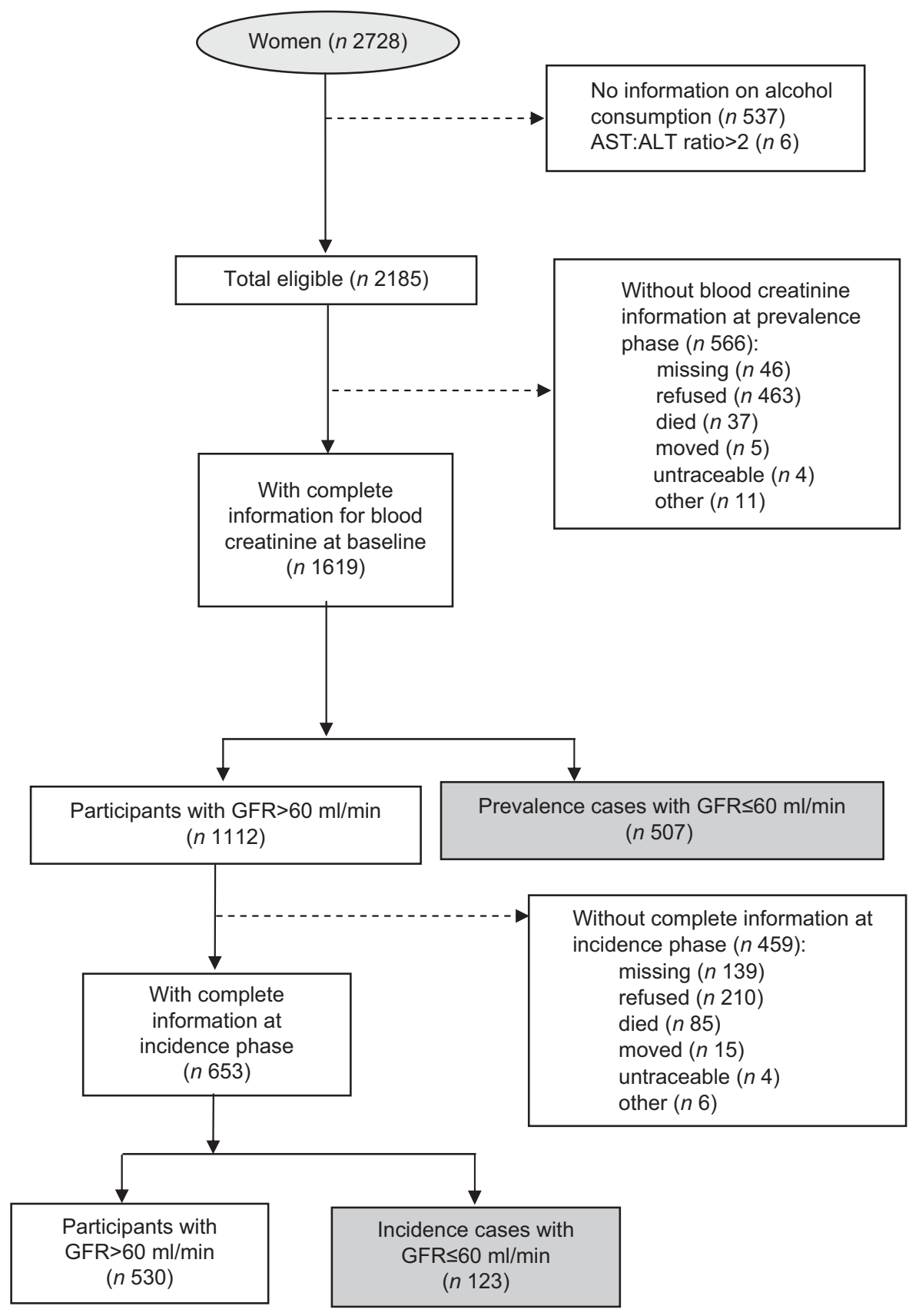

Fig. 1 Attrition analysis for women: elderly Italians aged 65-84 years, Italian Longitudinal Study on Aging

Total individual alcohol consumption $(\mathrm{g} / \mathrm{d})$ was calculated by multiplying the amount of beverage $(\mathrm{ml} / \mathrm{d})$ consumed by the amount of alcohol contained in each beverage $(\mathrm{g} / \mathrm{ml})$, as recommended by the Italian National Institute of Nutrition $^{(13)}$, and summing each amount. To be precise, we assumed that wine has an alcohol content of $9 \cdot 4 \mathrm{~g} / 100 \mathrm{ml}$, beer $3.6 \mathrm{~g} / 100 \mathrm{ml}$ and spirits $28.8 \mathrm{~g} / 100 \mathrm{ml}$. For the men, the total daily alcohol intake was classified into six alcohol consumption brackets: lifelong abstainers, former drinkers, drinkers of $\leq 12 \mathrm{~g}$ alcohol/d, 13-24 g alcohol/d, 25-47 g alcohol $/ \mathrm{d}$ and $\geq 48 \mathrm{~g}$ alcohol/d. For the women, the last two categories were pooled ( $>24 \mathrm{~g} /$ alcohol d).
Smoking habit was also considered, i.e. the mean number of cigarettes smoked daily. Those who had never smoked were classified as never smokers and those who smoked $>5$ cigarettes/d were classified as smokers, either current smokers or former smokers (those who had given up smoking at least 5 years before the baseline investigation).

\section{Blood sampling, blood pressure and anthropometric measurements}

Venous blood samples were drawn from each individual after an overnight fast. The blood tests and measurement methods are described elsewhere ${ }^{(12)}$. Briefly, serum 


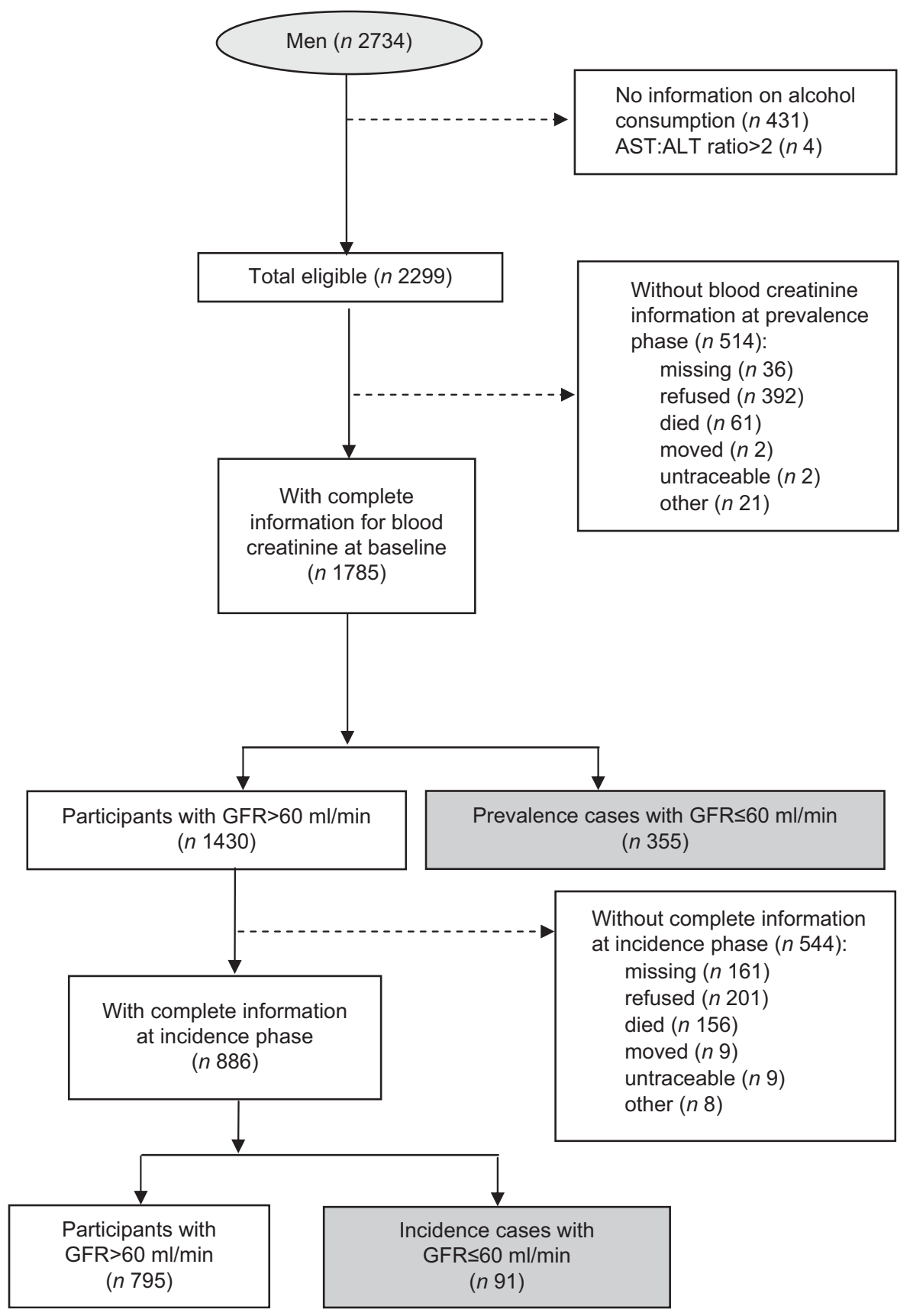

Fig. 2 Attrition analysis for men: elderly Italians aged 65-84 years, Italian Longitudinal Study on Aging

creatinine, glycaemia, plasma fibrinogen and serum TAG, LDL cholesterol (LDL-C), HDL cholesterol (HDL-C) and total cholesterol were measured.

Renal function was estimated using the simplified Modification of Diet in Renal Diseases formula, i.e. glomerular filtration rate $(\mathrm{GFR})=186 \times[$ serum creatinine $(\mathrm{mg} / \mathrm{dl})]^{-1 \cdot 154} \times(\text { age })^{-0.203} \times(0.742 \text { for females })^{(14)}$. This formula is the preferred method of estimation in elderly people ${ }^{(15)}$. No adjustment for race was considered because all our patients were white. All GFR values were expressed as $\mathrm{ml} / \mathrm{min}$ per $1.73 \mathrm{~m}^{2}$ body surface area. A reduced GFR was defined as $60 \mathrm{ml} / \mathrm{min}$ or less.
Systolic and diastolic blood pressure values were obtained by averaging the measures taken during the interview, the physical examination and the clinical examination. In data analysis, isolated systolic hypertension was defined as systolic pressure $>160 \mathrm{mmHg}$ and diastolic pressure $<90 \mathrm{mmHg}$.

Height and weight were measured with people barefoot and lightly dressed, from which BMI was calculated.

\section{Statistical analysis}

All statistical analyses were stratified by gender. To generalize the ILSA sample to the Italian population and to 
take into account the design effect, a set of weights was defined and applied according to the age distribution of the Italian reference population and the sample fraction. The general characteristics of the participants at baseline were compared by alcohol consumption level. The parametric or non-parametric approach was used, as applicable, for the ANOVA to compare mean values. Distributions of categorical variables (education, smoking habit, diseases) were compared with the $\chi^{2}$ test. The percentage change in serum creatinine compared with the baseline value was calculated as [(follow-up - baseline value)/baseline value] $\times 100$.

Multiple adjusted least-square means of serum creatinine levels and percentage changes in serum creatinine levels, and the standard error, were calculated using ANOVA within alcohol consumption groups. The adjusting variables were age, BMI, smoking habit, history of hypertension and diabetes at baseline.

The prevalence of low GFR $(\leq 60 \mathrm{ml} / \mathrm{min})$ at baseline was calculated with $95 \%$ CI. Logistic regression analysis was used to estimate OR and $95 \% \mathrm{CI}$ for the presence of low GFR, using the alcohol consumption classes as independent variable. Data from the literature suggest there are many factors, potential confounders or intermediates, of alcohol consumption on renal impairment. Age, education, smoking, protein intake and antihypertensive and lipid-lowering drugs were considered confounders, because these factors are involved in renal impairment and in our data are associated with alcohol consumption. As for protein intake, we used BMI as a surrogate of protein metabolic charge. Meanwhile, as alcohol consumption is thought to act potentially on blood cholesterol and fibrinogen, systolic hypertension and diabetes, all of these variables were qconsidered intermediate factors of alcohol action. Based on this, we performed three logistic regression models to assess confounding and to investigate mediation. The first logistic regression model was unadjusted (model 1); model 2 produced OR adjusting for potential confounding variables; and model 3 included potential confounders also adjusting for potential intermediates of alcohol action.

The linear trend of the OR was assessed by treating alcohol consumption as a ranked variable in the logistic models. A quadratic term for alcohol consumption was entered in the models to evaluate if the association was U-shaped. Analysis of trend was performed excluding former drinkers.

The analysis of incident worsening in renal function included only those participants with GFR $>60 \mathrm{ml} / \mathrm{min}$ at baseline. The cumulative incidence of low GFR at the follow-up in 1995 was calculated with the related $95 \%$ CI. We compared the risk of low GFR in different alcohol consumption groups, taking abstainers as the reference. To adjust for confounders and intermediates, the three logistic models previously applied were used to estimate adjusted OR for incidence data. Corrected risk ratios (RR) were approximated from $\mathrm{OR}^{(16)}$.
To explore the effect of plausible competing risks on the relationships between alcohol consumption and renal function, as suggested by the preliminary analysis on participants who were excluded, a sensitivity analysis was performed by applying the previously described models only on participants free from main chronic disease at baseline (heart failure, myocardial infarction, hypertension, stroke, diabetes).

In all analyses, the threshold for significance was set at two-tailed $0 \cdot 05$. Statistical analyses were performed with the SAS statistical software package version 9.1 (SAS Institute, Cary, NC, USA).

\section{Results}

In our sample of 1619 elderly women, 477 were lifelong abstainers, 358 former drinkers and 784 were current drinkers. The female drinkers had a mean (sD) alcohol consumption of $16 \cdot 0(1 \cdot 0) \mathrm{g} / \mathrm{d}$, median $11.7 \mathrm{~g} / \mathrm{d}$ (first quartile $=$ $11.7 \mathrm{~g} / \mathrm{d}$, third quartile $=15.4 \mathrm{~g} / \mathrm{d}$ ). Their mean (SD) daily alcohol intake from wine, beer and spirits was $14.5(8.9) \mathrm{g} / \mathrm{d}$, $0.3(1.4) \mathrm{g} / \mathrm{d}$ and $1.4(8.5) \mathrm{g} / \mathrm{d}$, respectively.

Among our 1785 elderly men, 138 were lifelong abstainers, 315 former drinkers and 1332 were current drinkers. Among the male drinkers, the mean (SD) alcohol consumption was $31 \cdot 0(26 \cdot 4) \mathrm{g} / \mathrm{d}$, median $23.3 \mathrm{~g} / \mathrm{d}$ (first quartile $=11 \cdot 0 \mathrm{~g} / \mathrm{d}$, third quartile $=37 \cdot 8 \mathrm{~g} / \mathrm{d}$ ). Their mean (SD) daily alcohol intake from wine, beer and spirits was $26 \cdot 6(22 \cdot 6) \mathrm{g} / \mathrm{d}, 0.5(2 \cdot 3) \mathrm{g} / \mathrm{d}$ and $3.9(9 \cdot 7) \mathrm{g} / \mathrm{d}$, respectively. Almost all of these Italian drinkers drank wine ( $98 \%$ of the men and $99 \%$ of the women).

More detailed results on alcohol consumption in the ILSA can be found in the report by Scafato et al. ${ }^{(17)}$.

Tables 1 and 2 compare the characteristics of the sample population by drinking category. Among the women, blood fibrinogen $(P=0 \cdot 0002)$ and the prevalence of diabetes $(P<0 \cdot 0001)$ were significantly and inversely associated with alcohol intake, while smoking habit $(P=0.0002)$ and serum albumin $(P=0 \cdot 0001)$ were directly and significantly associated with alcohol consumption (Table 1). Among the men, formal education, blood fibrinogen and serum creatinine were significantly and inversely associated with alcohol intake at baseline $(P<0.0001, P=0.005$ and $P=0 \cdot 005$, respectively), while smoking habit $(P=0 \cdot 003)$, HDL-C $(P=0 \cdot 005)$, LDL-C $(P=0 \cdot 001)$ and systolic blood pressure $(P=0.0008)$ were directly and significantly associated with alcohol consumption (Table 2).

Figure 3 shows the adjusted mean serum creatinine levels at baseline by gender and alcohol intake level. The analysis considered only the 1539 subjects for whom sufficient information was obtained in the incidence phase. The difference between alcohol intake groups was statistically significant only for the men $(P=0 \cdot 02)$, with lower mean serum creatinine levels among higher drinking categories. 
Table 1 Women's characteristics at baseline by alcohol consumption (weighted data), Italian Longitudinal Study on Aging

\begin{tabular}{|c|c|c|c|c|c|c|c|c|c|c|c|}
\hline \multirow[b]{2}{*}{ WOMEN } & \multicolumn{2}{|c|}{$\begin{array}{l}\text { Abstainers } \\
\text { (n 477) }\end{array}$} & \multicolumn{2}{|c|}{$\begin{array}{l}\text { Former } \\
(n 358)\end{array}$} & \multicolumn{2}{|c|}{$\begin{array}{l}\leq 12 \mathrm{~g} / \mathrm{d} \\
(n \text { 479) }\end{array}$} & \multicolumn{2}{|c|}{$\begin{array}{c}13-24 \mathrm{~g} / \mathrm{d} \\
(n 224)\end{array}$} & \multicolumn{2}{|c|}{$\begin{array}{c}>24 \mathrm{~g} / \mathrm{d} \\
(n 81)\end{array}$} & \multirow[b]{2}{*}{$P$} \\
\hline & Mean & SD & Mean & SD & Mean & SD & Mean & SD & Mean & SD & \\
\hline Age (years) & $72 \cdot 5$ & $5 \cdot 9$ & $73 \cdot 6$ & $6 \cdot 0$ & $73 \cdot 3$ & $6 \cdot 0$ & $73 \cdot 2$ & $6 \cdot 0$ & $73 \cdot 3$ & $5 \cdot 6$ & 0.06 \\
\hline BMI $\left(\mathrm{kg} / \mathrm{m}^{2}\right)$ & $27 \cdot 4$ & $6 \cdot 0$ & $28 \cdot 4$ & $5 \cdot 4$ & $27 \cdot 3$ & $5 \cdot 2$ & $27 \cdot 3$ & $6 \cdot 0$ & $27 \cdot 8$ & $5 \cdot 3$ & 0.09 \\
\hline SBP $(\mathrm{mmHg})$ & $149 \cdot 3$ & $19 \cdot 1$ & $150 \cdot 5$ & $20 \cdot 3$ & $149 \cdot 8$ & $19 \cdot 2$ & $147 \cdot 0$ & $18 \cdot 1$ & $151 \cdot 1$ & $17 \cdot 8$ & $0 \cdot 20$ \\
\hline DBP (mmHg) & $83 \cdot 8$ & $9 \cdot 0$ & $82 \cdot 7$ & $9 \cdot 1$ & 83.5 & $8 \cdot 7$ & $83 \cdot 6$ & $9 \cdot 2$ & $85 \cdot 4$ & $8 \cdot 7$ & 0.09 \\
\hline Albumin (g/dl) & $4 \cdot 2$ & 0.5 & $4 \cdot 1$ & 0.5 & $4 \cdot 2$ & $0 \cdot 4$ & $4 \cdot 3$ & 0.5 & $4 \cdot 3$ & 0.4 & 0.0001 \\
\hline TAG (mg/dl) & $155 \cdot 8$ & $91 \cdot 1$ & $152 \cdot 5$ & $86 \cdot 4$ & $145 \cdot 0$ & $75 \cdot 2$ & $139 \cdot 6$ & $69 \cdot 0$ & $138 \cdot 9$ & $64 \cdot 0$ & 0.04 \\
\hline LDL-C (mg/dl) & $151 \cdot 0$ & $45 \cdot 9$ & $144 \cdot 5$ & $39 \cdot 5$ & $152 \cdot 6$ & $43 \cdot 6$ & $155 \cdot 2$ & $45 \cdot 2$ & $156 \cdot 1$ & $43 \cdot 6$ & 0.02 \\
\hline HDL-C (mg/dl) & $50 \cdot 0$ & $12 \cdot 1$ & $49 \cdot 5$ & $11 \cdot 6$ & $50 \cdot 6$ & $13 \cdot 4$ & $51 \cdot 4$ & $12 \cdot 3$ & $51 \cdot 1$ & $11 \cdot 8$ & 0.46 \\
\hline Fibrinogen (mg/dl) & $381 \cdot 7$ & $107 \cdot 4$ & $368 \cdot 0$ & $102 \cdot 9$ & $362 \cdot 6$ & $92 \cdot 8$ & $355 \cdot 6$ & $97 \cdot 3$ & $337 \cdot 7$ & $88 \cdot 3$ & 0.0002 \\
\hline \multirow[t]{2}{*}{ Creatinine (mg/dl) } & 0.92 & 0.59 & 0.91 & $0 \cdot 38$ & $0 \cdot 89$ & $0 \cdot 22$ & 0.87 & $0 \cdot 19$ & $0 \cdot 87$ & $0 \cdot 19$ & $0 \cdot 46$ \\
\hline & \multicolumn{2}{|c|}{$\%$} & \multicolumn{2}{|c|}{$\%$} & \multicolumn{2}{|c|}{$\%$} & \multicolumn{2}{|c|}{$\%$} & \multicolumn{2}{|c|}{$\%$} & \\
\hline \multicolumn{12}{|l|}{ Smoking habit (\%) } \\
\hline Never smoked & \multicolumn{2}{|c|}{$\begin{array}{r}90.0 \\
2.6\end{array}$} & \multicolumn{2}{|c|}{$89 \cdot 7$} & \multicolumn{2}{|c|}{$93 \cdot 3$} & \multicolumn{2}{|c|}{88.9} & \multicolumn{2}{|c|}{$77 \cdot 5$} & 0.002 \\
\hline Former smoker & \multirow{2}{*}{\multicolumn{2}{|c|}{$\begin{array}{l}2 \cdot 6 \\
7 \cdot 4\end{array}$}} & \multirow{2}{*}{\multicolumn{2}{|c|}{$\begin{array}{l}3 \cdot 6 \\
6 \cdot 7\end{array}$}} & \multirow{2}{*}{\multicolumn{2}{|c|}{$\begin{array}{l}1 \cdot 8 \\
4.9\end{array}$}} & \multirow{2}{*}{\multicolumn{2}{|c|}{$\begin{array}{l}4 \cdot 4 \\
6 \cdot 7\end{array}$}} & & & \\
\hline Smoker & & & & & & & & & \multicolumn{2}{|c|}{$14 \cdot 6$} & \\
\hline \multicolumn{12}{|l|}{ Formal education } \\
\hline None-3 years in primary school & \multicolumn{2}{|c|}{$40 \cdot 8$} & \multicolumn{2}{|c|}{$58 \cdot 0$} & \multicolumn{2}{|c|}{$52 \cdot 2$} & \multicolumn{2}{|c|}{$41 \cdot 5$} & 41 . & & $<0 \cdot 0001$ \\
\hline 4 years in primary-secondary school & & $5 \cdot 7$ & & $3 \cdot 6$ & 39 & $\cdot 4$ & 45 & & 42 . & & \\
\hline High school-university & & .5 & & $3 \cdot 4$ & & 4 & 12 & & 16 . & & \\
\hline Diuretics (\%) & & $3 \cdot 1$ & & .1 & 36 & 5 & 36 & & 43. & & $0 \cdot 61$ \\
\hline ACE inhibitors (\%) & & $3 \cdot 9$ & & $1 \cdot 2$ & 23 & 4 & 23 & & 34 . & & $0 \cdot 01$ \\
\hline NSAID (\%) & & 2.0 & & $3 \cdot 1$ & 13 & 9 & 10 & & 17 . & & 0.06 \\
\hline History of hypertension (\%) & & $3 \cdot 8$ & & $5 \cdot 8$ & 72 & 0 & 69 & & 78 . & & $0 \cdot 33$ \\
\hline History of diabetes (\%) & & $\cdot 1$ & & $\cdot 1$ & 10 & $\cdot 3$ & & 6 & 8. & 9 & $<0.0001$ \\
\hline History of angina (\%) & & 7.5 & & $3 \cdot 8$ & & 9 & & 0 & 3. & $\cdot 4$ & $0 \cdot 32$ \\
\hline History of infarction (\%) & & $5 \cdot 9$ & & $5 \cdot 4$ & & .2 & & 9 & 7. & $\cdot 3$ & $0 \cdot 24$ \\
\hline History of stroke (\%) & & $6 \cdot 4$ & & $3 \cdot 0$ & & 1 & & $\cdot 8$ & 1. & · 3 & 0.22 \\
\hline
\end{tabular}

SBP, systolic blood pressure; DBP, diastolic blood pressure; LDL-C, LDL cholesterol; HDL-C, HDL cholesterol; ACE, angiotensin-converting enzyme; NSAID, non-steroidal anti-inflammatory drugs.

Figure 4 shows the adjusted mean serum creatinine levels at follow-up by gender and alcohol intake level. The difference between alcohol intake groups was again statistically significant only for the men $(P=0 \cdot 04)$, lower mean serum creatinine levels coinciding with the heavier drinkers.

Table 3 shows the prevalence of reduced renal function (GFR $\leq 60 \mathrm{ml} / \mathrm{min}$ ) at baseline and the results of the adjusted logistic regression models evaluating the association between low GFR and different alcohol consumption groups by comparison with abstainers. Despite the figures, alcohol consumption did not seem to correlate significantly with the prevalence of low GFR in the elderly women and no linear or quadratic terms were statistically significant in any logistic model. For the elderly men, a significant decreasing linear trend $(P=0 \cdot 05)$ was shown in the risk of low GFR at baseline with alcohol categories in model 2, and after adjusting for both confounders and intermediates in model 3 the significance was marginal $(P=0 \cdot 08)$.

Table 4 gives the adjusted RR for low GFR by comparison with abstainers in the incidence phase by alcohol consumption level. For women the risk of low GFR was not statistically associated with alcohol consumption level. The linear trend was never statistically significant, but in model 2 the quadratic term was marginally significant
$(P=0 \cdot 06)$. In men, adjusted RR for drinking categories were all lower than 1 , even though statistical significance was reached only for former drinkers $(\mathrm{RR}=0 \cdot 18,95 \% \mathrm{CI}$ $0 \cdot 04,0 \cdot 85)$. The linearity of trend showed marginal significance only in model $2(P=0 \cdot 06)$.

The additional results provided by the sensitivity analyses only including participants free from chronic diseases at baseline (data not shown) supported the linearity of relationships between alcohol consumption and prevalent renal dysfunction in both genders (model 3: $P$ for linear trend $=0.006$ and 0.07 for women and men, respectively), while a U-shaped relationship with incidence of renal impairment was confirmed only in women (model 3: $P$ for quadratic term $=0 \cdot 05$ ).

\section{Discussion}

The present study investigated the relationship between moderate alcohol consumption and age-related loss of renal function. Only in men did both prevalence and incidence results seem to suggest an inverse linear relationship between moderate alcohol consumption and the risk of age-related loss of renal function. The results suggest that alcohol might not exert a harmful effect on kidney function in elderly men. In contrast a U-shaped 
Table 2 Men's characteristics at baseline by alcohol consumption (weighted data), Italian Longitudinal Study on Aging

\begin{tabular}{|c|c|c|c|c|c|c|c|c|c|c|c|c|c|}
\hline \multirow[b]{2}{*}{ MEN } & \multicolumn{2}{|c|}{ Abstainers ( $n$ 138) } & \multicolumn{2}{|c|}{ Former $(n 315)$} & \multicolumn{2}{|c|}{$\leq 12 \mathrm{~g} / \mathrm{d}(n 340)$} & \multicolumn{2}{|c|}{$13-24 \mathrm{~g} / \mathrm{d}(n 441)$} & \multicolumn{2}{|c|}{$25-47 \mathrm{~g} / \mathrm{d}$ (n 332) } & \multicolumn{2}{|c|}{$\geq 48 \mathrm{~g} / \mathrm{d}(n 219)$} & \multirow[b]{2}{*}{$P$} \\
\hline & Mean & SD & Mean & SD & Mean & SD & Mean & SD & Mean & SD & Mean & SD & \\
\hline Age (years) & $70 \cdot 6$ & 4.9 & $72 \cdot 7$ & 4.9 & $72 \cdot 6$ & $5 \cdot 0$ & $71 \cdot 7$ & $5 \cdot 1$ & $71 \cdot 6$ & $5 \cdot 0$ & $71 \cdot 4$ & $4 \cdot 8$ & 0.0003 \\
\hline BMI $\left(\mathrm{kg} / \mathrm{m}^{2}\right)$ & $26 \cdot 9$ & $4 \cdot 4$ & $26 \cdot 3$ & $3 \cdot 4$ & $26 \cdot 2$ & $3 \cdot 5$ & $26 \cdot 3$ & $3 \cdot 4$ & $26 \cdot 7$ & $3 \cdot 4$ & $26 \cdot 9$ & 4.9 & $0 \cdot 16$ \\
\hline $\mathrm{SBP}(\mathrm{mmHg})$ & $143 \cdot 4$ & $18 \cdot 0$ & $143 \cdot 7$ & $16 \cdot 7$ & $147 \cdot 5$ & $16 \cdot 0$ & $146 \cdot 6$ & $16 \cdot 5$ & $146 \cdot 4$ & $16 \cdot 6$ & $150 \cdot 1$ & $16 \cdot 4$ & 0.0008 \\
\hline $\mathrm{DBP}(\mathrm{mmHg})$ & $84 \cdot 0$ & $10 \cdot 3$ & $81 \cdot 6$ & $8 \cdot 1$ & $82 \cdot 9$ & $8 \cdot 1$ & 83.5 & $8 \cdot 1$ & $83 \cdot 7$ & $8 \cdot 7$ & $83 \cdot 8$ & $7 \cdot 8$ & 0.02 \\
\hline Albumin (g/dl) & $4 \cdot 4$ & $0 \cdot 4$ & $4 \cdot 3$ & 0.5 & $4 \cdot 3$ & $0 \cdot 4$ & $4 \cdot 3$ & $0 \cdot 4$ & $4 \cdot 3$ & $0 \cdot 4$ & $4 \cdot 3$ & $0 \cdot 4$ & 0.08 \\
\hline TAG (mg/dl) & $164 \cdot 8$ & $85 \cdot 3$ & $147 \cdot 6$ & 74.5 & $152 \cdot 2$ & $65 \cdot 8$ & $145 \cdot 0$ & $72 \cdot 5$ & $148 \cdot 7$ & $72 \cdot 7$ & $163 \cdot 1$ & 93.5 & 0.04 \\
\hline LDL-C (mg/dl) & $133 \cdot 1$ & $34 \cdot 4$ & $127 \cdot 4$ & $36 \cdot 3$ & $128 \cdot 5$ & $35 \cdot 9$ & $135 \cdot 1$ & $33 \cdot 8$ & $137 \cdot 1$ & $35 \cdot 6$ & $139 \cdot 4$ & $35 \cdot 0$ & 0.001 \\
\hline HDL-C (mg/dl) & $45 \cdot 5$ & $9 \cdot 3$ & $47 \cdot 7$ & $12 \cdot 5$ & $48 \cdot 5$ & $10 \cdot 0$ & $46 \cdot 7$ & $7 \cdot 9$ & $48 \cdot 8$ & $11 \cdot 1$ & $49 \cdot 0$ & $10 \cdot 3$ & 0.005 \\
\hline Fibrinogen (mg/dl) & $351 \cdot 2$ & $82 \cdot 1$ & $346 \cdot 3$ & $97 \cdot 8$ & $355 \cdot 9$ & $86 \cdot 4$ & $339 \cdot 7$ & $83 \cdot 7$ & $334 \cdot 7$ & $96 \cdot 2$ & $325 \cdot 4$ & $83 \cdot 6$ & 0.005 \\
\hline \multirow[t]{2}{*}{ Creatinine $(\mathrm{mg} / \mathrm{dl})$} & $1 \cdot 11$ & $0 \cdot 30$ & $1 \cdot 13$ & $0 \cdot 37$ & $1 \cdot 11$ & 0.28 & $1 \cdot 10$ & 0.50 & 1.05 & 0.34 & $1 \cdot 01$ & 0.19 & 0.005 \\
\hline & \multicolumn{2}{|c|}{$\%$} & \multicolumn{2}{|c|}{$\%$} & \multicolumn{2}{|c|}{$\%$} & \multicolumn{2}{|c|}{$\%$} & \multicolumn{2}{|c|}{$\%$} & \multicolumn{2}{|c|}{$\%$} & \\
\hline \multicolumn{14}{|l|}{ Smoking habit (\%) } \\
\hline Never smoked & \multicolumn{2}{|c|}{$31 \cdot 1$} & \multicolumn{2}{|c|}{$38 \cdot 0$} & \multicolumn{2}{|c|}{$38 \cdot 8$} & \multicolumn{2}{|c|}{$36 \cdot 4$} & \multicolumn{2}{|c|}{$35 \cdot 8$} & \multicolumn{2}{|c|}{$27 \cdot 7$} & 0.003 \\
\hline Former smoker & \multicolumn{2}{|c|}{$44 \cdot 8$} & \multirow{2}{*}{\multicolumn{2}{|c|}{$\begin{array}{l}45 \cdot 3 \\
16 \cdot 7\end{array}$}} & \multirow{2}{*}{\multicolumn{2}{|c|}{$\begin{array}{l}40 \cdot 4 \\
20 \cdot 8\end{array}$}} & \multirow{2}{*}{\multicolumn{2}{|c|}{$\begin{array}{l}38 \cdot 5 \\
25 \cdot 1\end{array}$}} & \multirow{2}{*}{\multicolumn{2}{|c|}{$\begin{array}{l}35 \cdot 9 \\
28 \cdot 3\end{array}$}} & \multirow{2}{*}{\multicolumn{2}{|c|}{$\begin{array}{l}37 \cdot 5 \\
34 \cdot 8\end{array}$}} & \\
\hline Smoker & & & & & & & & & & & & & \\
\hline Formal education & & & & & & & & & & & & & \\
\hline None-3 years in primary school & & & & & & & & & & & & & $<0.0001$ \\
\hline 4 years in primary-secondary school & & & & & & & & & & & & & \\
\hline High school-university & & & & & & & & & & & & & \\
\hline Diuretics (\%) & & & & & & & & & & & & & 0.65 \\
\hline ACE inhibitors (\%) & & & & & & & & & & & & & $0 \cdot 28$ \\
\hline NSAID (\%) & & & & & & & & & & & & & 0.24 \\
\hline History of hypertension (\%) & & & & & & & & & & & & & $0 \cdot 30$ \\
\hline History of diabetes (\%) & & & & & & & & & & & & & $0 \cdot 17$ \\
\hline History of angina (\%) & & & & & & & & & & & & & $0 \cdot 18$ \\
\hline History of infarction (\%) & & & & & & & & & & & & & 0.53 \\
\hline History of stroke (\%) & & & & & & & & & & & & & 0.03 \\
\hline
\end{tabular}

SBP, systolic blood pressure; DBP, diastolic blood pressure; LDL-C, LDL cholesterol; HDL-C, HDL cholesterol; ACE, angiotensin-converting enzyme; NSAID, non-steroidal anti-inflammatory drugs. 


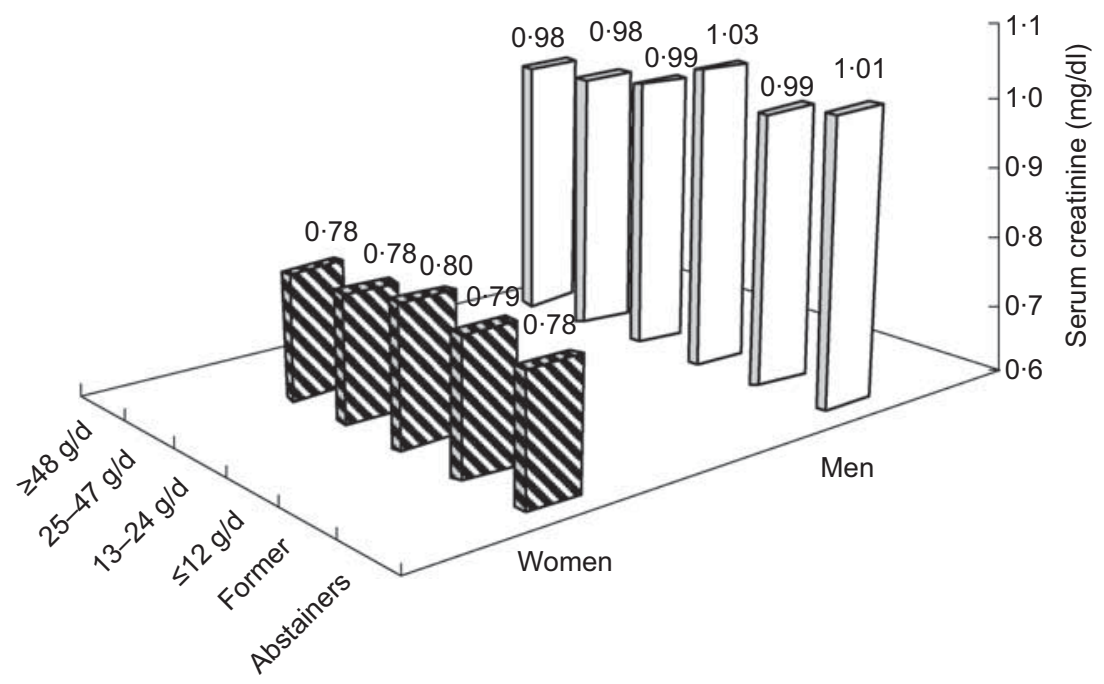

Fig. 3 Adjusted mean serum creatinine levels at baseline by gender and alcohol consumption: elderly Italians aged 65-84 years, Italian Longitudinal Study on Aging. The analysis considered 653 women and 886 men included in the incidence phase of the study. Mean values were adjusted for BMI, age, smoking, education, hypertension and diabetes at baseline (weighted data). Significance of the difference in serum creatinine by alcohol consumption group: $P=0.33$ (women) and $P=0.02$ (men)

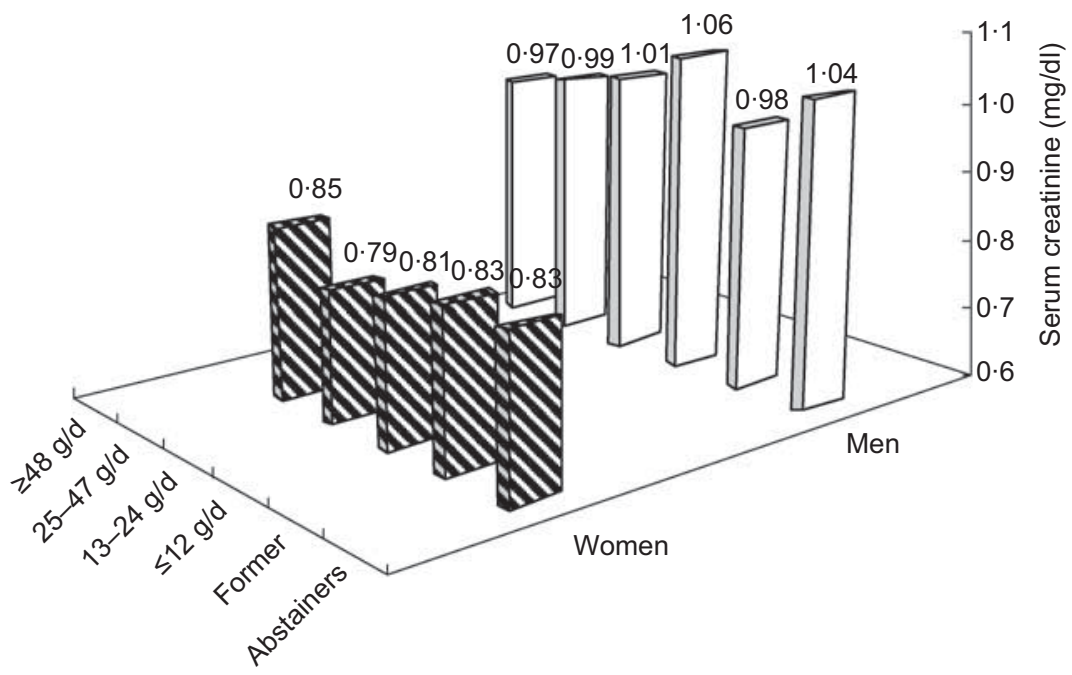

Fig. 4 Adjusted mean serum creatinine levels at the 3.5-year follow-up by gender and alcohol consumption: elderly Italians 65-84 years, Italian Longitudinal Study on Aging. The analysis considered 653 women and 886 men included in the incidence phase of the study. Mean values were adjusted for BMI, age, smoking, education, hypertension and diabetes at baseline (weighted data). Significance of the difference in serum creatinine by alcohol consumption group: $P=0.12$ (women) and $P=0.04$ (men)

association was shown for women at the incidence phase, suggesting a higher risk of developing renal impairment in elderly women who drink more than $24 \mathrm{~g}$ alcohol $/ \mathrm{d}$.

The kidneys of elderly people show morphological and haemodynamic alterations that determine a progressive age-associated decline in renal function. On the other hand, several studies have shown that the age-related loss of kidney function is more pronounced in older patients in whom cardiovascular and other risk factors coexist, suggesting a strong relationship between worsening kidney function and hypertension, diabetes mellitus, hyperlipidaemia and smoking, as well as non-traditional cardiovascular risk factors including inflammation and endothelial dysfunction ${ }^{(3,18)}$. The latter factors are also involved in kidney atherosclerotic development, responsible for a so-called ischaemic nephropathy, which is associated with progressive renal fibrosis and therefore with worsening renal function. Actually, the present study confirmed the prognostic role on worsening of renal function of factors such as use of diuretics, smoking and high fibrinogen levels (data not shown), as suggested previously ${ }^{(19)}$.

The mechanisms which link alcohol consumption to kidney function can draw on the mechanisms advanced to explain the effects of alcohol consumption on cardiovascular 
Table 3 Prevalence of renal dysfunction (defined as GFR $\leq 60 \mathrm{ml} / \mathrm{min}$ ) by alcohol consumption category and OR ratios and $95 \% \mathrm{Cl}$ (estimated with weighted data) obtained from logistic regression models. Abstainers are the reference group

\begin{tabular}{|c|c|c|c|c|c|c|c|c|}
\hline & \multicolumn{2}{|c|}{ Prevalence of renal dysfunction } & \multicolumn{2}{|c|}{ Model 1} & \multicolumn{2}{|c|}{ Model 2} & \multicolumn{2}{|c|}{ Model 3} \\
\hline & $\%$ & $95 \% \mathrm{Cl}$ & OR & $95 \% \mathrm{Cl}$ & OR & $95 \% \mathrm{Cl}$ & OR & $95 \% \mathrm{Cl}$ \\
\hline \multicolumn{9}{|l|}{ Women* } \\
\hline Abstainers & $30 \cdot 4$ & $26 \cdot 5,34 \cdot 3$ & 1.00 & & $1 \cdot 00$ & & $1 \cdot 00$ & \\
\hline Former & $30 \cdot 1$ & $25 \cdot 5,34 \cdot 6$ & 0.98 & $0.74,1.31$ & 0.73 & $0.51,1.04$ & $0 \cdot 70$ & $0.48,1.02$ \\
\hline$<12 \mathrm{~g} / \mathrm{d}$ & $30 \cdot 9$ & $26 \cdot 9,34 \cdot 8$ & $1 \cdot 02$ & $0.79,1 \cdot 33$ & 0.94 & $0.68,1 \cdot 31$ & 0.94 & $0.67,1.33$ \\
\hline $12-24 \mathrm{~g} / \mathrm{d}$ & $28 \cdot 5$ & $22 \cdot 9,34 \cdot 1$ & 0.91 & $0.66,1.27$ & 0.88 & $0.58,1.34$ & 0.86 & $0.55,1.34$ \\
\hline $25-47 \mathrm{~g} / \mathrm{d}$ & $21 \cdot 9$ & $13 \cdot 3,30 \cdot 5$ & 0.64 & $0 \cdot 38,1 \cdot 10$ & 0.51 & $0.26,0.99$ & 0.57 & $0.28,1.17$ \\
\hline$\geq 48 \mathrm{~g} / \mathrm{d}$ & - & & - & & - & & - & \\
\hline & \multirow{2}{*}{\multicolumn{2}{|c|}{$\begin{array}{c}\text { Linear trend } P \\
\text { Quadratic trend } P\end{array}$}} & 0.28 & & 0.13 & & $0 \cdot 30$ & \\
\hline & & & $0 \cdot 15$ & & 0.20 & & 0.30 & \\
\hline \multicolumn{9}{|c|}{ 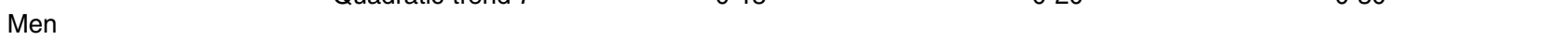 } \\
\hline Abstainers & $18 \cdot 4$ & $11 \cdot 7,25 \cdot 1$ & 1.00 & & $1 \cdot 00$ & & 1.00 & \\
\hline Former & $20 \cdot 5$ & $15 \cdot 5,25 \cdot 5$ & $1 \cdot 14$ & $0.66,1.96$ & 0.91 & $0.47,1.27$ & 1.02 & $0.50,2 \cdot 10$ \\
\hline$<12 \mathrm{~g} / \mathrm{d}$ & $21 \cdot 3$ & $16 \cdot 5,26 \cdot 1$ & $1 \cdot 20$ & $0.70,2 \cdot 04$ & 0.81 & $0.42,1.58$ & 0.93 & $0.46,1.90$ \\
\hline $12-24 \mathrm{~g} / \mathrm{d}$ & $18 \cdot 8$ & $14 \cdot 9,22 \cdot 7$ & 1.03 & $0 \cdot 61,1 \cdot 72$ & 0.75 & $0.40,1.42$ & 0.83 & $0.41,1.65$ \\
\hline $25-47 \mathrm{~g} / \mathrm{d}$ & $13 \cdot 5$ & $9 \cdot 5,17 \cdot 5$ & 0.69 & $0.40,1.22$ & 0.62 & $0.31,1.23$ & 0.69 & $0.33,1.46$ \\
\hline \multirow[t]{3}{*}{$\geq 48 \mathrm{~g} / \mathrm{d}$} & $10 \cdot 1$ & $5 \cdot 8,14 \cdot 4$ & 0.50 & $0.26,0.95$ & 0.52 & $0.24,1 \cdot 12$ & 0.59 & $0.26,1.37$ \\
\hline & \multirow{2}{*}{\multicolumn{2}{|c|}{$\begin{array}{l}\text { Linear trend } P \\
\text { Quadratic trend } P\end{array}$}} & 0.004 & & 0.05 & & 0.08 & \\
\hline & & & 0.02 & & 0.72 & & $0 \cdot 61$ & \\
\hline
\end{tabular}

GFR, glomerular filtration rate.

Model 1, unadjusted OR; model 2, OR adjusted for covariates (age, BMI, smoking habit ( $>20$ cigarettes/d), education, antihypertensive and lipid-lowering drugs) at baseline; model 3, OR adjusted for covariates (age, BMI, smoking habit (>20 cigarettes/d), education, antihypertensive and lipid-lowering drugs) and intermediates (isolated systolic hypertension, diabetes, blood fibrinogen and total cholesterol) at baseline.

${ }^{*}$ For women, the highest drinker category is $>24 \mathrm{~g} / \mathrm{d}$.

Table 4 Incidence of renal dysfunction (defined as GFR $\leq 60 \mathrm{ml} / \mathrm{min}$ ) by alcohol consumption category and $\mathrm{RR}^{\star}$ and $95 \% \mathrm{Cl}$ (estimated with weighted data) performed by different models. Abstainers are the reference group

\begin{tabular}{|c|c|c|c|c|c|c|c|c|}
\hline & \multicolumn{2}{|c|}{ Incidence of renal dysfunction } & \multicolumn{2}{|c|}{ Model 1} & \multicolumn{2}{|c|}{ Model 2} & \multicolumn{2}{|c|}{ Model 3} \\
\hline & $\%$ & $95 \% \mathrm{Cl}$ & $\mathrm{RR}$ & $95 \% \mathrm{Cl}$ & RR & $95 \% \mathrm{Cl}$ & $\mathrm{RR}$ & $95 \% \mathrm{Cl}$ \\
\hline \multicolumn{9}{|l|}{ Woment } \\
\hline Abstainers & $23 \cdot 6$ & $17 \cdot 9,29 \cdot 9$ & $1 \cdot 00$ & & $1 \cdot 00$ & & $1 \cdot 00$ & \\
\hline Former & $21 \cdot 6$ & $15 \cdot 5,27 \cdot 7$ & 0.91 & $0.62,1.31$ & $1 \cdot 21$ & $0 \cdot 77,1 \cdot 76$ & $1 \cdot 25$ & $0.76,1.88$ \\
\hline$<12 \mathrm{~g} / \mathrm{d}$ & $13 \cdot 5$ & $9 \cdot 3,18 \cdot 7$ & 0.58 & $0.37,0.87$ & $0 \cdot 72$ & $0.41,1 \cdot 17$ & $0 \cdot 87$ & $0.47,1.39$ \\
\hline $12-24 \mathrm{~g} / \mathrm{d}$ & $12 \cdot 2$ & $6 \cdot 1,18 \cdot 4$ & 0.52 & $0.29,0.90$ & 0.50 & $0.22,1.02$ & 0.61 & $0 \cdot 27,1 \cdot 25$ \\
\hline $25-47 \mathrm{~g} / \mathrm{d}$ & $21 \cdot 6$ & $8 \cdot 5,34 \cdot 7$ & 0.92 & $0.46,1.65$ & $1 \cdot 25$ & $0.57,2 \cdot 25$ & $1 \cdot 27$ & $0.50,2.45$ \\
\hline$\geq 48 \mathrm{~g} / \mathrm{d}$ & - & & - & & - & & - & \\
\hline & \multirow{2}{*}{\multicolumn{2}{|c|}{$\begin{array}{l}\text { Linear trend } P \\
\text { Quadratic trend } P\end{array}$}} & 0.02 & & 0.32 & & 0.34 & \\
\hline & & & 0.04 & & 0.06 & & 0.35 & \\
\hline \multicolumn{9}{|l|}{ Men } \\
\hline Abstainers & $11 \cdot 8$ & $3 \cdot 6,20 \cdot 1$ & 1.00 & & 1.00 & & 1.00 & \\
\hline Former & 6.9 & $2 \cdot 2,11 \cdot 6$ & 0.58 & $0.21,1.51$ & 0.25 & $0.06,1.04$ & 0.20 & $0.05,0.87$ \\
\hline$<12 \mathrm{~g} / \mathrm{d}$ & $15 \cdot 8$ & $9 \cdot 6,21 \cdot 9$ & $1 \cdot 33$ & $0.59,2.69$ & 0.87 & $0.29,1.91$ & $0 \cdot 72$ & $0.22,2.03$ \\
\hline $12-24 \mathrm{~g} / \mathrm{d}$ & $7 \cdot 3$ & $3.8,10 \cdot 9$ & 0.62 & $0.25,1.42$ & 0.72 & $0.24,1.93$ & 0.62 & $0 \cdot 20,1 \cdot 75$ \\
\hline $25-47 \mathrm{~g} / \mathrm{d}$ & $5 \cdot 8$ & $2 \cdot 1,9 \cdot 4$ & 0.49 & $0 \cdot 17,1 \cdot 24$ & 0.26 & $0.07,0.99$ & 0.29 & $0.07,1.10$ \\
\hline \multirow[t]{3}{*}{$\geq 48 \mathrm{~g} / \mathrm{d}$} & $6 \cdot 4$ & $2 \cdot 0,10 \cdot 8$ & 0.54 & $0 \cdot 19,1 \cdot 42$ & $0 \cdot 61$ & $0 \cdot 18,1 \cdot 88$ & 0.72 & $0 \cdot 20,2 \cdot 16$ \\
\hline & \multirow{2}{*}{\multicolumn{2}{|c|}{ Linear trend $P$}} & 0.01 & & 0.06 & & $0 \cdot 19$ & \\
\hline & & & 0.45 & & 0.99 & & 0.65 & \\
\hline
\end{tabular}

GFR, glomerular filtration rate; RR, risk ratio.

Model 1, unadjusted OR; model 2, OR adjusted for covariates (age, BMI, smoking habit (>20 cigarettes/d), education, antihypertensive and lipid-lowering drugs) at baseline; model 3, OR adjusted for covariates (age, BMI, smoking habit (>20 cigarettes/d), education, antihypertensive and lipid-lowering drugs) and intermediates (isolated systolic hypertension, diabetes, blood fibrinogen and total cholesterol) at baseline.

${ }^{*}$ Risk ratios were approximated from the adjusted odds ratios obtained using multivariable logistic regression models.

tFor women, the highest drinker category is $>24 \mathrm{~g} / \mathrm{d}$.

diseases and risk factors ${ }^{(19)}$. Recent experimental and human observations indicate that some other components of alcoholic beverages might have beneficial effects on kidney function by influencing oxidative stress, endothelial dysfunction and apoptotic mechanisms which play a role in many diseases, including atherosclerosis and several nephropathies ${ }^{(20)}$. In addition, it was shown that alcohol consumption increases paraoxonase activity $^{(21)}$ and the latter potently inhibits lipoprotein oxidation $^{(22)}$. It has also been shown that alcohol consumption is associated with healthier blood levels of HDL-C and apo A1. Shaeffner et al. ${ }^{(23)}$ found that men with HDL-C levels $<40 \mathrm{mg} / \mathrm{dl}$ had a twofold risk of renal insufficiency after adjusting for other risk factors. Actually our sample 
population mainly consumes wine (more than $85 \%$ of total alcohol intake) and this does not allow us to analyse alcohol separately from other components. As a consequence, our results cannot be enlarged to drinking habits based on different alcoholic beverages. Nevertheless, our results corroborate findings in the literature.

Referring to inflammatory markers and renal impairment, it has recently been suggested that chronic hypoxia and inflammation are common mechanisms of progressive renal fibrosis, which is associated with worsening renal function. A leading role in this process is played by plasminogen activator inhibitor-1, which facilitates extracellular matrix accumulation by inhibiting plasmin-dependent extracellular matrix degradation. In their epidemiological study, Mukamal et al. found that adults with moderate alcohol consumption had lower plasminogen activator inhibitor antigen-1 levels than non-drinkers ${ }^{(24)}$. There are numerous reports of alcohol consumption in adults and older people being associated with lower blood fibrinogen levels ${ }^{(1)}$ and fibrinogen is a component strongly associated with the progressive deterioration of renal function ${ }^{(25)}$.

Another far from negligible effect of alcohol has to do with its influence on insulin sensitivity and the incidence of diabetes. Alcohol consumption is associated with type 2 diabetes in a U-shaped fashion, indicating a lower risk of type 2 diabetes in moderate alcohol consumers than in abstainers or heavy drinkers, and this applies to older women too ${ }^{(26)}$.

On the other hand, alcohol consumption has a harmful effect on systolic and diastolic blood pressure levels, which are risk factors for renal function, as amply demonstrated ${ }^{(27)}$. Our results nevertheless suggest that the overall direction of association of alcohol leans towards a non-detrimental effect on renal function in elderly men.

Furthermore, in our analysis the adjusted results obtained from the model including known intermediate factors were very similar to those obtained from the model adjusting only for confounders. These results seem to suggest that other mechanisms should be involved in the likely association between alcohol and renal function.

The association of alcohol consumption on renal impairment appeared to differ in women and men. Among women alcohol consumption was related to renal impairment with a U-shaped dose effect, while in men a decreasing linear trend for the risk of renal dysfunction among drinking categories was shown. Actually, our results are in agreement with previous evidence on sexspecific susceptibility to alcohol effects. Men and women differ in their ability to metabolize alcohol, possibly due to gender-related differences in total fluid distribution volume, lean body mass, or activity of the enzymes processing alcohol in the liver ${ }^{(28)}$. Sex steroids may have a role in cytochrome enzyme expression and in regulating hepatic oxidant stress status ${ }^{(29)}$. The overall result is a higher susceptibility of women to alcohol action, exposing women to harmful effects also for low doses.
The present study suffers from a number of limitations. First, information about alcohol consumption was selfreported; however, alcohol consumption is very common in Italy (particularly among older people) and so reporting on drinking habits is unlikely to cause embarrassment. Second, no information was obtained on drinking patterns; participants were not asked about the proportions of alcohol they drank with meals or at other times. Third, as wine was by far the most common alcoholic beverage used by our sample, we cannot distinguish between the specific contribution to our findings of alcohol per se and of other components of the alcoholic beverages. Fourth, the FFQ was not validated and it did not allow us to evaluate daily nutrient intake. Fifth, even though the study was population-based and the sample size was remarkable, attrition heavily reduced the sample size of critical groups, in particular women drinking more than $24 \mathrm{~g}$ alcohol/d and male abstainers. This caused inadequate power in the statistical analyses and consequently, although the results suggested well-defined trends, statistical significance of the difference was only roughly achieved. Moreover, our results could be affected by risks due to those diseases that could compete with alcohol consumption on health outcomes. In fact, those who drink large amounts of alcohol may die from other causes such as heart failure, diabetes or myocardial infarction. Nevertheless the sensitivity analysis performed only on participants free from chronic diseases at prevalence phase confirmed the results. Finally, as this was an observational study, a causal interpretation of the relationship between the exposure and the outcome is not allowed.

\section{Conclusions}

Our results suggest a not harmful association of moderate alcohol consumption on the risk of renal impairment in elderly men. In accordance with the recommendations on alcohol consumption in the elderly and subject to individual characteristics, moderate quantities of alcohol may not have an injurious association on renal function in the elderly and perhaps even a beneficial association for men and for women at very light consumption (less than $24 \mathrm{~g} / \mathrm{d}$ ) only. The mechanisms of alcohol on the cardiovascular system might also be invoked to explain the results on renal function. Nevertheless, in translating the results of the research into general policy on alcohol consumption we cannot forget the proved harmful causal relationship between alcohol and mortality for a high number of diseases directly or indirectly deriving from any consumption, and the adverse effects of alcohol on risk of falling and interactions with medication. Furthermore, special warning is necessary for drinking among women because of their major vulnerability to alcohol effects that, even at light intake, would significantly raise their risk of developing diseases. 


\section{Acknowledgements}

Sources of funding: The Italian National Research Council supported the ILSA project from 1991 to 1998 as part of the Progetto Finalizzato Invecchiamento and in 1999 as part of the 'Biology of Aging' Strategic Project. Since 1999 ILSA has been coordinated by the National Centre for Epidemiology, Surveillance and Health Promotion CNESPS Population Health Unit at the Istituto Superiore di Sanità and funded by the Ministero della Sanità through the programme 'Epidemiology of the Elderly' and the 'Estimates of Health Needs of the Elderly' special programme of the Tuscany Region. Conflicts of interest: None. Author contributions: guarantors for the integrity of the study: E.M. and E.S.; study conception and design: A. Buja, E.P., G.S. and S.M.; intellectual content: E.P., A. Buja, G.R. and S.G.; statistical analysis: E.P. and A. Buja; data interpretation: A. Buja, S.M., E.S., B.B. and A. Basile; manuscript writing: E.P., A. Buja and G.S. All authors read and approved the final manuscript. Acknowledgements: The ILSA Working Group comprises the following individuals. E. Scafato (MD), G. Farchi (MSc), L. Galluzzo (MA) and C. Gandin (MD), Istituto Superiore di Sanità, Roma; A. Di Carlo (MD) and M. Baldereschi (MD), CNR, Firenze; G. Crepaldi (MD), S. Maggi (MD), N. Minicucci $(\mathrm{PhD})$ and $\mathrm{M}$. Noale (PhD), CNR, Aging Section, Padova; A. Capurso (MD), F. Panza (MD, PhD), V. Solfrizzi (MD, $\mathrm{PhD})$, V. Lepore (MD) and P. Livrea (MD), University of Bari; L. Motta (MD), G. Carnazzo (MD), M. Motta (MD) and P. Bentivegna (MD), University of Catania; S. Bonaiuto (MD), G. Cruciani (MD) and D. Postacchini (MD), Italian National Research Center on Aging, Fermo; D. Inzitari (MD) and L. Amaducci (MD), University of Firenze; C. Gandolfo (MD) and M. Conti (MD), University of Genova; N. Canal (MD) and M. Franceschi (MD), San Raffaele Institute, Milano; G. Scarlato (MD), L. Candelise (MD) and E. Scapini (MD), University of Milano; F. Rengo (MD), P. Abete (MD) and F. Cacciatore (MD), University of Napoli; G. Enzi (MD), L. Battistin (MD), G. Sergi (MD), F. Grigoletto $(\mathrm{ScD})$ and E. Perissinotto $(\mathrm{ScD})$, University of Padova; P. Carbonin (MD), Università Cattolica del Sacro Cuore, Roma.

\section{References}

1. Perissinotto E, Buja A, Maggi S et al. (2010) Alcohol consumption and cardiovascular risk factors in older lifelong wine drinkers: the Italian Longitudinal Study on Aging. Eur J Clin Nutr 64, 297-307.

2. Mukamal KJ, Chung H, Jenny NS et al. (2006) Alcohol consumption and risk of coronary heart disease in older adults: the Cardiovascular Health Study. J Am Geriatr Soc 54, 30-37.

3. Sarnak MJ \& Levey AS (2000) Cardiovascular disease and chronic renal disease: a new paradigm. Am J Kidney Dis 35, 4 Suppl. 1, S117-S131.

4. De Marchi S, Cecchin E, Basile A et al. (1993) Renal tubular dysfunction in chronic alcohol abuse - effects of abstinence. N Engl J Med 329, 1927-1934.
5. Reynolds K, Gu D, Chen J et al. (2008) Alcohol consumption and the risk of end-stage renal disease among Chinese men. Kidney Int 73, 870-876.

6. Schaeffner ES, Kurth T, de Jong PE et al. (2005) Alcohol consumption and the risk of renal dysfunction in apparently healthy men. Arch Intern Med 165, 1048-1053.

7. Knight EL, Stampfer MJ, Rimm EB et al. (2003) Moderate alcohol intake and renal function decline in women: a prospective study. Nephrol Dial Transplant 18, 1549-1554.

8. Stengel B, Tarver-Carr ME, Powe NR et al. (2003) Lifestyle factors, obesity and the risk of chronic kidney disease. Epidemiology 14, 479-487.

9. Perneger TV, Whelton PK, Puddey IB et al. (1999) Risk of end-stage renal disease associated with alcohol consumption. Am J Epidemiol 150, 1275-1281.

10. Vupputuri S \& Sandler DP (2003) Lifestyle risk factors and chronic kidney disease. Ann Epidemiol 13, 712-720.

11. Menon V, Katz R, Mukamal K et al. (2010) Alcohol consumption and kidney function decline in the elderly: alcohol and kidney disease. Nephrol Dial Transplant 25, 3301-3307.

12. Maggi S, Zucchetto M, Grigoletto F et al. (1994) The Italian Longitudinal Study on Aging (ILSA): design and methods. Aging (Milano) 6, 464-473

13. Istituto Nazionale di Ricerca per gli Alimenti e la Nutrizione (2003) Linee Guida per una Sana Alimentazione Italiana. Revision (2003). http://www.inran.it/files/download/linee_ gurda/ (accessed January 2011).

14. National Kidney Foundation (2002) K/DOQI clinical practice guidelines for chronic kidney disease: evaluation, classification, and stratification. Am J Kidney Dis 39, 2 Suppl. 1, S1-S266.

15. Fliser D (2008) Assessment of renal function in elderly patients. Curr Opin Nephrol Hypertens 17, 604-608.

16. Zhang J \& Yu KF (1998) What's the relative risk? A method of correcting the odds ratio in cohort studies of common outcomes. JAMA 280, 1690-1691.

17. Scafato E, Gandin C, Ghirini S et al. (2010) Epidemiologia e monitoraggio alcol-correlato in Italia. Valutazione dell'Osservatorio Nazionale Alcol-CNESPS sull'impatto dell'uso e abuso di alcol ai fini dell'implementazione delle attività del Piano Nazionale Alcol e Salute. Rapporto ISTISAN 10/5. http:// www.iss.it/binary/publ/cont/10cinqueWEB.pdf (accessed January 2011).

18. Elsayed EF, Tighiouart H, Griffith J et al. (2007) Cardiovascular disease and subsequent kidney disease. Arch Intern Med 167, 1130-1136.

19. Baggio B, Budakovic A, Perissinotto E et al. (2005) Atherosclerotic risk factors and renal function in the elderly: the role of hyperfibrinogenaemia and smoking. Results from the Italian Longitudinal Study on Ageing (ILSA). Nephrol Dial Transplant 20, 114-123.

20. Lo Presti R, Carollo C \& Caimi G (2007) Wine consumption and renal diseases: new perspectives. Nutrition 23, 598-602.

21. van der Gaag MS, van Tol A, Scheek LM et al. (1999) Daily moderate alcohol consumption increases serum paraoxonase activity; a diet-controlled, randomised intervention study in middle-aged men. Atherosclerosis 147, 405-410.

22. Watson AD, Berliner JA, Hama SY et al. (1995) Protective effect of high density lipoprotein associated paraoxonase inhibition of the biological activity of minimally oxidized low density lipoprotein. J Clin Invest 96, 2882-2891.

23. Schaeffner ES, Kurth T, Curhan GC et al. (2003) Cholesterol and the risk of renal dysfunction in apparently healthy men. J Am Soc Nephrol 14, 2084-2091.

24. Mukamal KJ, Jadhav PP, D'Agostino RB et al. (2001) Alcohol consumption and haemostatic factors: analysis of the Framingham Offspring cohort. Circulation 104, 1367-1373. 
25. Beulens JW, Stolk RP, van der Schouw YT et al. (2005) Alcohol consumption and risk of type 2 diabetes among older women. Diabetes Care 28, 2933-2938.

26. Buja A, Scafato E, Sergi G et al. (2010) Alcohol consumption and metabolic syndrome in the elderly: results from the Italian longitudinal study on aging. Eur J Clin Nutr 64, 297-307.

27. Xin X, He J, Frontini MG et al. (2001) Effects of alcohol reduction on blood pressure: a meta-analysis of randomized controlled trials. Hypertension $\mathbf{3 8}$, $1112-1117$.

28. Kwo PY, Ramchandani VA, O'Connor S et al. (1998) Gender differences in alcohol metabolism: relationship to liver volume and effect of adjusting for body mass. Gastroenterology 115, 1552-1557.

29. Wolbold R, Klein K, Burk O et al. (2003) Sex is a major determinant of CYP3A4 expression in human liver. Hepatology 38, 978-988. 